\title{
ROBUST GENERIC MODEL FEEDBACK UNDER MODEL UNCERTAINTIES: APPLICATION OF A TUBULAR REACTOR FOR THE TREATMENT OF INDUSTRIAL PLATING WASTEWATER
}

\author{
Ricardo Aguilar-López, Ricardo Acevedo-Gómez, María Isabel Neria González* and Alma Rosa \\ Domínguez-Bocanegra
}

\author{
Departamento de Biotecnología y Bioingeniería \\ CINVESTAV-IPN \\ Av. Instituto Politécnico Nacional No. 2508, San Pedro Zacatenco, México, D.F. 07360, MEXICO \\ E-mail.- raguilar@cinvestav.mx \\ Phone.- + 525557473800 , ext. 4307 \\ *División de Ingeniería Química y Bioquímica \\ Tecnológico de Estudios Superiores de Ecatepec \\ Av. Tecnológico s/n Esq. Av. Carlos Hank González Col. Valle de Anáhuac C.P. 55210, Ecatepec Estado de México
}

\section{ABSTRACT}

The goal of this work is to describe the design of a feedback controller to regulate the Hexavalent chromium $(\mathrm{Cr}(\mathrm{VI}))$ concentration in industrial plating wastewater in a tubular reactor. $\mathrm{Cr}(\mathrm{VI})$ is a major pollutant present in industrial wastewaters common to the metal and mineral processing as well as to plating industries. For control purposes, a dynamic model of a plug flow reactor with dispersion is developed in the form of partial differential equations (PDE) via applying classical conservation principles; this model is experimentally corroborated using laboratory data. The proposed controller is based on uncertainty observer to infer unknown terms as diffusive transport and $\mathrm{Cr}(\mathrm{VI})$ kinetic rate; also Generic Model Controller (GMC) is coupled with this estimation methodology to provide robustness against model uncertainties. The controller leads to nonlinear PID plus double integral action, where the tuning rules are given in terms of the observer and GMC gains. A theoretical frame is given in order to show the stability properties of the closed-loop system under the proposed controller. Numerical simulation illustrates performance of the methodology proposed; a comparison with observer based I/O linearizing controller and a well tuned PID controller is done, which allows concluding that the observer based Generic Model Controller exhibits better performance.

KEY WORDS: $\mathrm{Cr}(\mathrm{VI})$ treatment, GMC, Tubular reactor, Infinite dimensional models, Robust performance.

\section{RESUMEN}

El objetivo del presente trabajo es describir el diseño de un controlador retroalimentado para regular la concentración de Cromo Hexavalente $(\mathrm{Cr}(\mathrm{VI}))$ de agua residual de la industria de galvanoplastía en un reactor tubular. El $\mathrm{Cr}(\mathrm{VI})$ es uno de los más tóxicos contaminantes de esta industria. Para fines de control, se diseña un modelo dinámico del proceso, el cual es un reactor flujo pistón con dispersión descrito por ecuaciones diferenciales parciales que se basa en la aplicación de los principios básicos de balances de masa; este modelo se corrobora experimentalmente con datos de laboratorio. El controlador propuesto se basa en un estimador de incertidumbres con el fin de inferir los términos relacionados con el transporte difusivo de masa y la cinética de remoción de $\mathrm{Cr}(\mathrm{VI})$, que se asumen desconocidas; posteriormente, este estimador se acopla con un controlador de modelo genérico para generar un esquema de control robusto contra incertidumbres. El diseño del controlador propuesto es equivalente a una estructura de tipo PID más una acción doble integral no lineal, donde las reglas de sintonizado se dan en términos de las ganancias del observador de incertidumbres y del propio controlador genérico. Se proporciona el marco teórico que muestra que la metodología propuesta produce estabilidad a lazo cerrado. Simulaciones numéricas muestran el desempeño de la metodología 
propuesta; se realiza una comparación con un controlador linealizante basado en observador y un controlador lineal clásico PID; esto permite concluir que la estrategia de control propuesta tiene el mejor desempeño.

Palabras clave: Tratamiento de $\mathrm{Cr}(\mathrm{VI})$, control de modelo genérico, reactor tubular, modelos de dimensión infinita, desempeño robusto

\section{INTRODUCTION}

Tubular reactors are very important processes equipments in chemical industry because of their ability to provide large continuous production, avoiding mechanical issues because of mixing with important energy saving. Currently, the adequate operation and control of tubular reactors is a challenging issue for control engineers because these systems exhibited distributed parameters; i.e. the reactor's variables depend on position and time. Tubular reactors are mathematically modeled by nonlinear Partial Differential Equations (PDE) derived from first principles application (mass, energy momentum balances, chemical kinetics, thermodynamics), reason why the analysis from the classical control theory point of view (where the models are described by Ordinary Differential Equations) turns not to be enough.

In contrast, process engineers have been employing linear controllers, including PI/PID compensators. There are many reasons for this, among them the adequate understanding of the process operation given by the long history in the employment of linear compensators, besides others advantages such as emergency manual modes, automatic and manual switching and set point tracking. However, despite successful industrial operation of linear control, so far, there is a lack of theoretical results to back up its regulation capacity and robust designs.

The problem of feedback control design for PDE has been considered by several authors (e.g. Balas, 1979; Chistofides, 1998; Chistofides and Dautidis, 1998; Froment and Bischoff, 1990), the resulting controllers depend on spatial coordinates. The control designs mentioned above do not look satisfactory at all because in industrial process the controllers act at the boundary of the process; where the control output is the fluid flow at the inlet of the process (Froment and Bischoff, 1990; Aguilar et al., 2002).

Meanwhile, several papers describing alternative control designs for tubular reactors have been presented. In these works, the main idea is to transform the PDE models (infinite dimensional model) into finite set of ordinary differential equations (ODE) (finite dimensional models) via discretization techniques such as finite differences, finite element, orthogonal collocation, etc. where the goal is to regulate the process at some specific point, generally at process output conditions (Aguilar et al., 2002; Dochain, Babary and Tali-mammar, 1992; González et al., 1999). However, these approaches lack information because of considering the control design procedure on finite dimensional models; consequently, the robustness of these methodologies is only locally assured.

In this work, a strategy that considers the distributed nature of tubular reactors is developed to design the control avoiding information loss. An electrochemical tubular reactor for the treatment of $\mathrm{Cr}(\mathrm{VI})$ from industrial plating wastewater is considered as study case, considering the diffusive transport and the kinetic term as model uncertainties. An uncertainty estimator is coupled with the Generic Model Control Law in order to provide proper robust properties, given by the integral action considered in this control technique (Lee and Sullivan, 1988; Signal and Lee, 1992). The methodology proposed is equivalent to a nonlinear PID plus double integral controller, it is compared to an observer based I/O linearizing controller and a well tuned linear PID controller; computer simulation shows that the best performance of the three methodologies is exhibited by the observer-based GMC controller 


\section{PROCESS DESCRIPTION}

$\mathrm{Cr}(\mathrm{VI})$ appears to be carcinogenic; even in small quantities it irritates plant and animal tissues being a strong oxidizing agent easily absorbed by the skin. Health effects of chromium are related to the valence state of the metal and the time of exposure. Trivalent chromium ( $\mathrm{Cr}$ [III]) is an essential dietary mineral in low doses. $\mathrm{Cr}(\mathrm{VI})$ is generally considered 1,000 times more toxic than $\mathrm{Cr}$ (III) (Department of Health and Human Services, 2000). Some electroplating, leather tanning, and textile industries release relatively large amounts of chromium in water bodies; in addition, solid wastes from chromate-processing facilities have been disposed improperly in landfills and they are sources of contamination for groundwater. This water pollutant is able to display considerable diffusion rates through soils and aquatic environments.

Several treatment processes have been proposed in order to diminish $\mathrm{Cr}(\mathrm{VI})$ concentrations from industrial wastes including chemical precipitation, ion exchange, evaporation and reverse osmosis. In these kinds of methods, an excess dosage of 2.5 times the theoretical addition of chemical agents (ferrous sulphate) must be applied in order to complete the reaction. Therefore, it produces big quantities of sludge, increasing the cost of the process due to the treatment, handling and disposal of this sludge.

Electrochemical $\mathrm{Cr}(\mathrm{VI})$ reduction is an alternative process which has been studied and applied successfully to remove $\mathrm{Cr}(\mathrm{VI})$ from wastewaters at laboratory level (Rodríguez et al., 2003). Reactions (I), (II), (III) and (IV) are considered to be present during the electrochemical process as shown in Figure 1. In fact, electrochemical processes have been proposed as an attractive alternative for $\mathrm{Cr}(\mathrm{VI})$ treatment because of their low process cost in comparison to traditional methods. After the electrolytic treatment, water can be reused in rinsing baths or can be discharged complying with environmental standards.

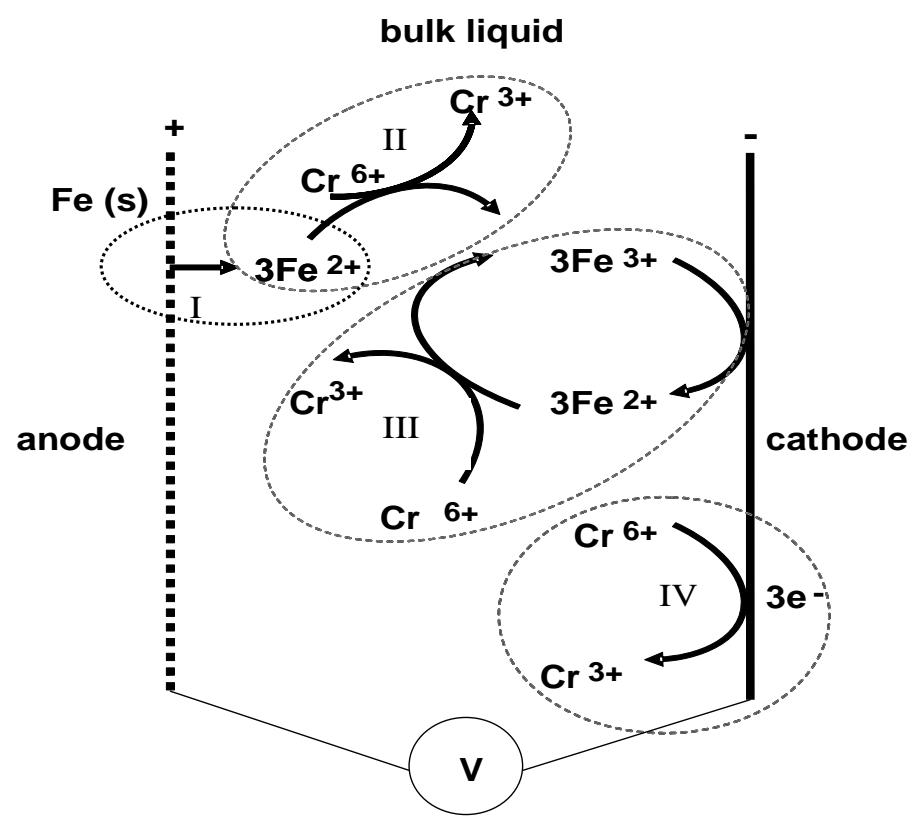

Figure 1. Summary of reactions of $\mathrm{Cr}(\mathrm{VI})$ reduction via electrochemical process.

Several types of electrochemical reactors, batch and continuous stirred tank reactors, have been previously studied (Rodríguez et al., 2004); however, mechanical mixing devices rise operating costs for stirred reactors. Therefore, a tubular electrochemical reactor seems adequate to perform economical and efficient removal of $\mathrm{Cr}(\mathrm{VI})$ from waste water. 


\subsection{CHROMIUM (VI) KINETIC REMOVAL MODEL}

In order to evaluate chemical kinetics, experimental data were obtained in a batch reactor of $170 \mathrm{~L}$. The electrochemical reactions that take place within the reactor can be summarized as follows:

In the anode:

$\mathrm{Fe}^{0}-2 \mathrm{e}^{-} \longrightarrow \mathrm{Fe}^{2+}$

In the solution:

$6 \mathrm{Fe}^{2+}+\mathrm{Cr}_{2} \mathrm{O}_{7}^{2-}+14 \mathrm{H}^{1+} \longrightarrow 6 \mathrm{Fe}^{3+}+2 \mathrm{Cr}^{3+}+7 \mathrm{H}_{2} \mathrm{O}$

Cathode reduction (Golub and Oren, 1988):

$\mathrm{Cr}_{2} \mathrm{O}_{7}{ }^{2-}+6 \mathrm{H}^{1+}+6 \mathrm{e}^{-} \longrightarrow \mathrm{Cr}_{2} \mathrm{O}_{4}{ }^{2-}+3 \mathrm{H}_{2} \mathrm{O}$

The $\mathrm{Cr}(\mathrm{VI})$ reduction as function of time is described by a kinetic model obtained that exhibits goodness of fit (Chi-square test) at 0.01 significance level (a 99\% confidence level). The experimental data were well fitted by a zero order equation at high $\mathrm{Cr}(\mathrm{VI})$ concentrations and by a first order reaction at low concentrations. The overall rate equation $\left(r_{\mathrm{Cr}}\right)$ with respect to the $\mathrm{Cr}(\mathrm{VI})$ in the liquid (Equation 4), was obtained employing the standard integral method (Froment and Bischoff, 1990). Experimental data and model (solid line) predictions are shown in Figure 2. As it can be seen, the reaction time to reach $0.5 \mathrm{mg}$ of $\mathrm{Cr}(\mathrm{VI}) / \mathrm{L}$ in the wastewater was 55 minutes (note the large operation time). The value of $0.5 \mathrm{mg} \mathrm{Cr}$ $(\mathrm{VI}) / \mathrm{L}$ was chosen because it is the maximum concentration of $\mathrm{Cr}(\mathrm{VI})$ permitted by Mexican environmental regulations.

$$
{ }^{\mathrm{r}} \mathrm{Cr}=\frac{\mathrm{k}_{1} \mathrm{Cr}}{1+\mathrm{kCr}}=\frac{0.7483 \mathrm{e}^{0.001 * \mathrm{I} \mathrm{Cr}}}{1+0.1772 \mathrm{e}^{-0.003 *{ }^{*} \mathrm{Cr}}}
$$

Here $I$ is the density electrical current, $190 \mathrm{~A} \cdot \mathrm{m}^{-2}$. 


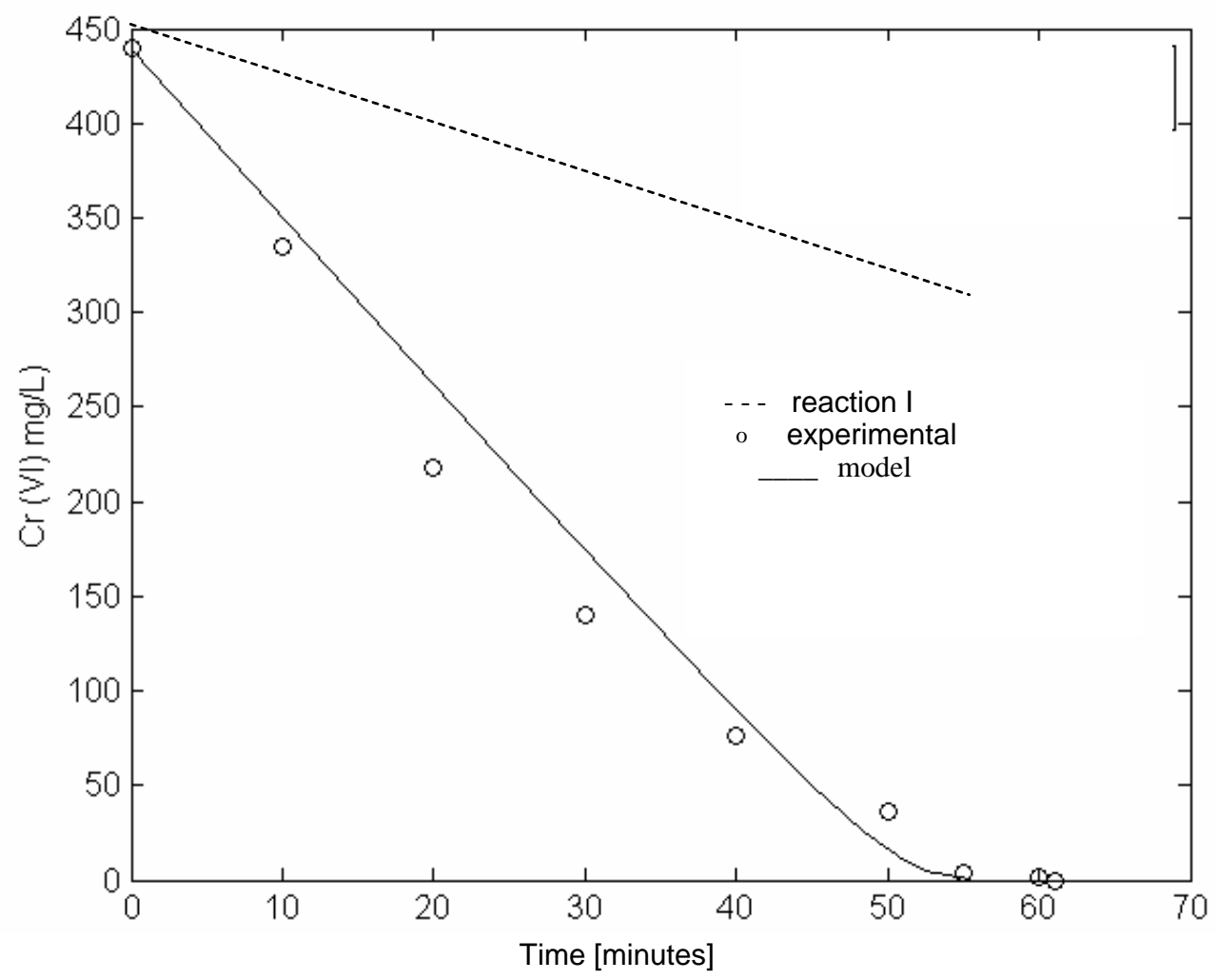

Figure 2. $\mathrm{Cr}(\mathrm{VI})$ concentration as a function of time at a I = $190 \mathrm{~A} / \mathrm{m} 2$ in the reactor (Volume $=170$

Liters)

\subsection{ELECTROCHEMICAL TUBULAR REACTOR}

In this work, an electrochemical tubular reactor containing a steel electrode is proposed to treat, in a continuous way, plating wastewater containing hexavalent chromium. Metal dissolution was electrochemically induced by applying a current density of $50 \mathrm{~A} \cdot \mathrm{m}-2$ by means of a direct current power supply. This process was performed in a plug flow reactor provided with steel electrodes, which consisted of 62 plates where 31 worked as anodes and the remainder as cathodes. The alternating stack of electrodes within the reactor was contained in an acrylic column of $1.295 \mathrm{~m}$ height and $0.064 \mathrm{~m}$ in diameter, whereby a cathode followed each anode. The area of each steel plate was $0.0001625 \mathrm{~m} 2$; so, total "sacrificial" electrode surface Se was 0.10075 m2. The column reactor (Figure 3) has four sampling ports at equal distances in which samples were collected to be analyzed in order to observe changes in $\mathrm{Cr}(\mathrm{VI})$ concentration as function of elapsed time and reactor distance. Conditions such as $\mathrm{pH}$ (adding $\mathrm{H} 2 \mathrm{SO} 4)$ and current density were maintained at the same value throughout the processing time. Synthetic wastewater solutions containing $\mathrm{Cr}(\mathrm{VI})$ were prepared using potassium dichromate (reagent grade) with known concentration of $\mathrm{Cr}(\mathrm{VI})$ of $130 \mathrm{mg} \cdot \mathrm{L}-1$ in distilled water in order to reach $\mathrm{pH}=2$. $\mathrm{Cr}(\mathrm{VI})$ concentration was also measured by treatment with 1-5-diphenylcarbohidrazide method (APHA, AWWA, WPCF, 1995); in this case, a Hach 3000 spectrophotometer was used and the absorption readings were obtained at $540 \mathrm{~nm}$. 


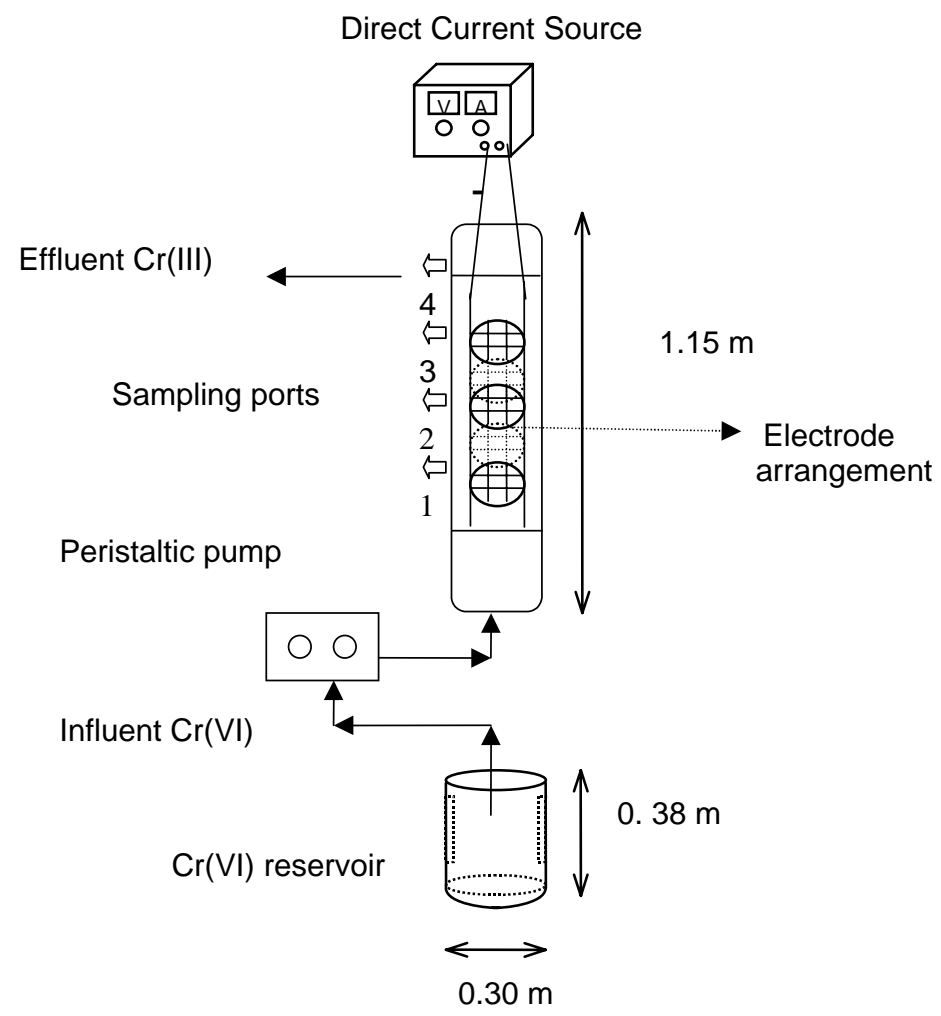

Figure 3. Schematic diagram of the electrochemical reactor.

The reactor was continuously feed with the aqueous solution containing $130 \mathrm{mg} \cdot \mathrm{L}^{-1}$ of $\mathrm{Cr}(\mathrm{VI})$. It becomes straightforward that a continuous $\mathrm{Cr}(\mathrm{VI})$ reduction of $98.5 \%(1,5 \mathrm{mg} / \mathrm{l})$ is achieved with a maximum flow rate of $338.61 \mathrm{~mL} \mathrm{~min}^{-1}$. It is important to note that despite the high conversion reached, the $\mathrm{Cr}(\mathrm{VI})$ concentration is $200 \%$ up of the $\mathrm{Cr}(\mathrm{VI})$ concentration required by the legislation $(0.5 \mathrm{mg} / \mathrm{l})$. A current density of $50 \mathrm{~A} \cdot \mathrm{m}^{-2}$ was imposed after the electrochemical reactor was filled with the solution using a tracer.

Dispersion coefficient was calculated as is it usual (Bird et al., 1962), resulting $\frac{D}{u L}=0.078$, used in the model of this work. This set of process conditions was previously reported by Soto et al. (2002).

One of the main drawbacks of the continuous operation for $\mathrm{Cr}(\mathrm{VI})$ treatment in wastewaters employing electrochemical reactors is the large open loop residence time of the process needed to reach the required $\mathrm{Cr}(\mathrm{VI})$ concentration at reactor output, as it is reported by Rodríguez et al. (2004a) and Rodríguez et al., (2004b). The large residence time is related to low processed flow rate of wastewater, which is undesirable for the reactor operating performance. In order to avoid it, some actions can be considered. One of them, it is to increase the $\mathrm{pH}$ inside the reactor to improve the kinetic rate conditions, but this action leads to high corrosion levels on the reactor. Another action is related to the increase of the density of the electrical current applied to the reactor, raising the economic operation cost, being inadequate too. 


\subsection{TUBULAR REACTOR MODELING}

Applying differential mass balance for the $\mathrm{Cr}(\mathrm{VI})$ concentration in the fluid phase, considering dispersion term in one-dimensional transport approach, the following dynamic plug flow reactor model is obtained:

$\frac{\partial C_{C r}}{\partial t}=D \frac{\partial^{2} C_{C r}}{\partial z^{2}}-\frac{\partial v_{z} C_{C r}}{\partial z}-{ }_{r} \frac{K_{1} C_{C r}}{1+K_{2} C_{C r}}$

Boundary conditions:

$$
\begin{aligned}
& C_{C r}=C_{C r 0} \quad \text { at } \quad z=0 \quad \forall t \\
& \frac{\partial C_{C r}}{\partial z}=0 \quad \text { at } \quad z=L \quad \forall t
\end{aligned}
$$

Initial condition:

$C_{C r}=C_{C r} *$ for $t=0 \quad \forall z$

Momentum balance to describe the velocity field for the axial coordinate of the reactor, considering the case where the momentum balance equation has not fluid dispersion:

$$
\frac{\partial v_{z}}{\partial t}=-v_{z} \frac{\partial v_{z}}{\partial z}
$$

Initial length condition:

$v_{z}(z, t)=v_{z}(t)$ at $z=0$

Initial time condition:

$v_{z}=v_{z 0} \quad$ for $\quad t=0 \quad \forall z$

This model was solved via finite differences, considering the operating conditions described; model and its simulation reproduces experimental data with satisfactory agreement (Figure 4).

\section{DESIGN OF THE CONTROL LAW}

Because of open-loop characteristics, operating policy for electrochemical reactors requires the application of control procedures, in this way, the reactor can be forced (via feedback control) to reach the $\mathrm{Cr}(\mathrm{VI})$ required by environmental legislation, to keep adequate processed wastewater flows and to save energy. For regulation purposes, the PDE model developed for the reactor is employed to design a robust controller. The considered measured process output is $\mathrm{Cr}(\mathrm{VI})$ concentration at reactor output conditions and the corresponding manipulated input is the input flow rate (velocity boundary condition at $\mathrm{z}=0)$ as usual.

In order to implement the control law, let us consider the following alternative $\mathrm{Cr}(\mathrm{VI})$ mass balance representation, assuming incompressible liquid; therefore, there is uniform velocity profile for the flow of disturbances along the reactor, i.e. $v_{z}(z, t)=u(t)$ : 
$\frac{\partial C_{C r}}{\partial t}=\varphi(z, t)-u(t) \frac{\Delta C_{C r}}{\Delta z}$

Here $\varphi(z, t)=D \frac{\partial^{2} C_{C r}}{\partial z^{2}}-C_{C r} \frac{\partial v_{z}}{\partial t}-\frac{k_{1} C_{C r}}{1+k_{2} C_{C r}}+D A E$

$D A E$ is the derivative approximation error of the $\mathrm{Cr}(\mathrm{VI})$ concentration gradient (i.e. $\left.\frac{\partial C_{C r}}{\partial z}=\frac{\Delta C_{C r}}{\Delta z}+D A E\right)$ and $u$ is the control input.

$\varphi$ is considered an uncertain term on the mass balance equation, it exhibits its own unknown dynamic behavior as

$\frac{\partial \varphi}{\partial t}=\gamma(z, t)$

In order to ensure that concentration of $\mathrm{Cr}(\mathrm{VI})$ will follow the desired behavior at reactor outlet, Generic Model Control (GMC) law is proposed. GMC has proved to be an effective tool to regulate nonlinear systems; it belongs to the family of generalized linearizing controllers, which under the assumption of knowledge of perfect model for the system, this controller cancel nonlinearities, imposing desired behavior. In particular GMC contains integral action that, as it is well known, induces robustness to the closed-loop behavior of the system.

The desired dynamic behavior of the system is proposed as

$$
\frac{\partial C_{C r}}{\partial t}=g_{1}^{-1}\left(C_{C r}-C_{C r-S P}\right)+\int_{0}^{t} g_{2}^{-1}\left(C_{C r}-C_{C r-S P}\right) d t
$$

Equation 10 represents stable behavior; from Equations (9) and (10) and applying the GMC stands, the ideal control law $u$ can be obtained, as follows:

$u=\frac{\Delta z}{\Delta C_{C r}}\left[g_{1}^{-1}\left(C_{C r}-C_{C r-S P}\right)+\int_{0}^{t} g_{2}^{-1}\left(C_{C r}-C_{C r-S P}\right)-\varphi(z, t)\right] \quad$ with $\quad \Delta C_{C r} \neq 0$

In order to ensure the corresponding restriction, $\Delta C_{C r}$ is considered the difference between the outlet and input $\mathrm{Cr}(\mathrm{VI})$ concentrations of the reactor, with $\Delta \mathrm{z}=\mathrm{L}$.

Note that the above controller is realizable if terms, especially $\varphi$, are known. However, $\varphi$ is considered uncertain, therefore standard GMC cannot be implemented. In order to supply this information, there are methodologies related to observers. Aguilar-López and collaborators have tried several observer designs for uncertain systems such as proportional, proportional-integral, sliding-mode, applied to systems modeled by ODEs (Aguilar-López and Maya-Yescas, 2005; Aguilar-López, 2003).

The system given by Equations (7)-(9) cannot be seen as a standard observer structure, which consists of a copy of the system plus correction of the measurement error; it is not possible since the term $\gamma(z, t)$ is an unknown function of the system output $C_{C r}$. Let us propose the following uncertainty observer: 
Robust generic model feedback under model uncertainties: application of a tubular reactor for the treatment of industrial plating wastewater,

$\dot{\hat{\varphi}}=\tau_{1}(\varphi-\hat{\varphi})+\tau_{2}(\dot{\varphi}-\dot{\hat{\varphi}})$

This uncertainty estimator is a reduced order observer, which infers the uncertain term $\varphi$. Note that the observer contains proportional and derivative actions, the aim of the derivative term is to improve the speed of the estimation algorithm because it enhances anticipatory and stabilizing effects of derivative actions and it is able to diminish the peaking phenomenon present in controllers based on observers (Sussman and Kokotovic, 1991). Introducing this observer, the non ideal controller is given by

$u=\frac{\Delta z}{\Delta C_{C r}}\left[g_{1}^{-1}\left(C_{C r}-C_{C r-S P}\right)+\int_{0}^{t} g_{2}^{-1}\left(C_{C r}-C_{C r-S P}\right)-\hat{\varphi}(z, t)\right]$

Now, the regulation error is defined by $e=Y-Y_{s p}=C_{C r}-C_{C r-S P}$. For this case $C_{C r-S P}=$ constant, consequently $\dot{e}=\frac{\partial C_{C r}}{\partial t}$. From mass balance equation, the uncertainty is $\varphi=\frac{\partial C_{C r}}{\partial t}-u \frac{\Delta C_{C r}}{\Delta z}$.

Now, substituting Equation (13) into it and taking the time derivative from the resulting equation, the following expression is obtained: $\dot{\varphi}=\left(g_{1}^{-1}+1\right) \ddot{e}-g_{2}^{-1} e+\dot{\hat{\varphi}}$. This derivative is introduced into Equation (12) to obtain $\dot{\hat{\varphi}}=\tau_{2}\left(g_{1}^{-1}+1\right) \ddot{e}+\left(\tau_{1}-\tau_{2} g_{2}^{-1}\right) \dot{e}-g_{1}^{-1} \tau_{1} e+\tau_{1} g_{2}^{-1} \int_{0}^{t} e(\sigma) d \sigma$. Integration of these equations yields:

$\hat{\varphi}=\tau_{2}\left(g_{1}^{-1}+1\right) \dot{e}+\left(\tau_{1}-\tau_{2} g_{2}^{-1}\right) e-\int g_{1}^{-1} \tau_{1} e(\sigma) d \sigma+\int_{0}^{t}\left(\tau_{1} g_{2}^{-1} \int_{0}^{t} e(\sigma) d \sigma\right) d \zeta$

The final expression for the input-output GMC controller with uncertainty estimation can be obtained substituting the above equation into the non-ideal controller (Equation 13), to obtain:

$u=\frac{\Delta z}{\Delta C_{C r}}\left[\left(g_{1}^{-1}+\left(\tau_{1}-\tau_{2} g_{2}^{-1}\right)\right) e+\left(g_{2}^{-1}-g_{1}^{-1} \tau_{1}\right) \int_{0}^{t} e(\sigma) d \sigma-\tau_{2}\left(g_{1}^{-1}+1\right) \dot{e}-\int_{0}^{t}\left(\tau_{1} g_{2}^{-1} \int_{0}^{t} e(\sigma) d \sigma\right] d \zeta\right]$

Note that this structure is equivalent to PID Controller plus double integral with time varying gains, where the tuning of the controller's gains depend of the closed-loop and measurement characteristic times of the system. 


\subsection{OBSERVER CONVERGENCE ANALYSIS}

A convergence analysis of the uncertainty observer should to be done.

Proposition 1. - Let $\varphi$ and $\hat{\varphi}$ be the uncertainty term and its estimate. The following dynamic system: $\dot{\hat{\varphi}}=\tau_{1}(\varphi-\hat{\varphi})+\tau_{2}(\dot{\varphi}-\dot{\hat{\varphi}})$ is an asymptotic-type reduced order observer for the system (9).

Proof 1. - Let us define the estimation error as

$$
\varepsilon=\varphi-\hat{\varphi}
$$

Now, the dynamic scalar equation of the estimation error according to Equation (9) and (12) is given by

$$
\dot{\varepsilon}=-\frac{\tau_{1}}{1+\tau_{2}} \varepsilon+\frac{\gamma(z, t)}{1+\tau_{2}}
$$

Integration of Equation (16) renders

$$
\varepsilon=\varepsilon_{0} \exp \left(-\frac{\tau_{1}}{1+\tau_{2}} t\right)+\int_{0}^{t} \exp \left(\frac{\tau_{1}}{1+\tau_{2}}(t-s)\right) \frac{\gamma(z, t)}{1+\tau_{2}} d s
$$

Now, consider the following assumption:

A1. - $\gamma(z, t)$ is bounded, i. e. $\|\gamma\| \leq \Psi$

Taking norms from Equation (18):

$$
\|\varepsilon\| \leq \exp \left(-\frac{\tau_{1}}{1+\tau_{2}} \mathrm{t}\right)\left(\left\|\varepsilon_{0}\right\|-\frac{\Psi}{\tau_{1}}\right)+\frac{\Psi}{\tau_{1}}
$$

In the limit when $\mathrm{t} \rightarrow \underline{\infty}$ :

$$
\|\varepsilon\| \leq \frac{\Psi}{\tau_{1}}
$$

\section{Remark 1}

It is important to analyze the structure of Equation (19) in order to obtain some characteristics of the proposed observer. As it can be observed, taking the limit, when $t \rightarrow \infty$, the estimation error remains around closed ball with radius proportional to $\frac{\Psi}{\tau_{1}}$, this radius can be made as small as desired by taken $\tau_{1}$ large enough. Besides, in order to improve the speed of the uncertainty observer convergence to the steady-state estimation error, two actions have to be taken. The first one is to consider parameter $\tau_{1}$ large enough, which is necessary to obtain a small steady-state error, as mentioned above, and the 
Robust generic model feedback under model uncertainties: application of a tubular reactor for the treatment of industrial plating wastewater,

R. Aguilar-López et al, 184-203

second one is faced with the influence of parameter $\tau_{2}$ related to the derivative action of the uncertainty observer. If $\tau_{2} \rightarrow-1$ then exponential term of the right hand side of Equation (19) can be accelerated enough and consequently, the convergence of the uncertainty observer exhibits a better performance.

\subsection{CLOSED-LOOP STABILITY ANALYSIS}

In order to assess closed-loop stability, the analysis departs from the mass balance closed-loop equation represented as follows:

$$
\begin{aligned}
& \frac{\partial e}{\partial t}=g_{1}^{-1} e+g_{2}^{-1} e_{1}+\varepsilon \\
& \frac{\partial e_{1}}{\partial t}=e
\end{aligned}
$$

Note that if not integral action were present (i.e. $g_{2}{ }^{-1}=0$ ), the closed-loop system would be related to a non homogeneous linear ordinary differential equation, with exogenous function $\varepsilon$ (estimation error), which is the standard observed based I/O linearizing control structure. One of the main drawbacks of this methodology is the so-called peaking phenomenon (Sussman and Kokotovic, 1991), such phenomenon can induce large overshoots which can lead to saturation of the control input; in addition, according to the general description of the windup phenomenon described by Rönnbäck (1997), the control signal can also be saturated due to large step changes in reference, even when a static control law is employed. In such situation, feedback is broken and the plant behaves as an open-loop system with a constant control input, allowing possible degradation of closed-loop performance. Now, considering the integral action introduced, it acts as to compensate the estimation error term $\varepsilon$, which helps to avoid the mentioned peaking and windup phenomenon.

Now, Equation (21) can be rewritten in vector notation as

$$
\frac{\partial E}{\partial t}=A E+\Pi
$$

Here:

$$
E=\left[\begin{array}{l}
e \\
e_{1}
\end{array}\right] ; \quad A=\left[\begin{array}{cc}
g_{1}^{-1} & g_{2}^{-1} \\
1 & 0
\end{array}\right] ; \quad \Pi=\left[\begin{array}{l}
\varepsilon \\
0
\end{array}\right]
$$

Matrix $A$ is Hurwitz stable by the adequate control's gain selection. Solving (22) renders

$$
E=E_{0} \exp (-A t)+\int_{0}^{t} \exp (-A t) \exp (A \sigma) \Pi d \sigma
$$

Here $E_{0}$ is the initial condition of the regulation error.

Let us take two additional assumptions:

A1.- $\Pi$ is bounded, i. e. $\|\Pi\| \leq \frac{\Psi}{\tau_{1}}$. 
A2. - If $\lambda_{1}, \lambda_{2}, . ., \lambda_{\mathrm{k}}$ are the distinct eigenvalues of Matrix $A$, where $\lambda_{\mathrm{j}}$ has multiplicity $n_{j}$ and $n_{1}+n_{2}+\ldots+$ $n_{k}=n$ and $\rho$ is any number larger than the real part of $\lambda_{1}, \lambda_{2}, \ldots, \lambda_{k}$, that is $\rho>\max \left(\Re e\left(\lambda_{j}\right)\right)$, then there exists a constant $j>0$ that satisfies

$\left\|\exp (A t) E_{a}\right\| \leq j \exp (-\rho t)\left\|E_{a}\right\|$

Taking norms of Equation (23), the following inequality arises and considering $\boldsymbol{A 1}$ and $\boldsymbol{A 2}$ :

$\left.0 \leq \lim _{t \rightarrow t_{0}}\|E\| \leq\left\|E_{0}\right\| \lim _{t \rightarrow t_{0}}\left[\| j \exp \left(-\rho \int d t\right)\right]\right]+\frac{\lim _{t \rightarrow t_{0}}\left[\int_{0}^{t}\left\|j \exp (\rho \sigma) \frac{\Psi}{\tau_{1}} d \sigma\right\|\right]}{\lim _{t \rightarrow t_{0}}\left\|j \exp \left(\int \rho d t\right)\right\|}$

The above equation means that the $\frac{\infty}{\infty}$ case of uniform L'höpital's rule can be applied as follows:

$0 \leq \lim _{t \rightarrow t_{0}}\|E(t)\| \leq \lim _{t \rightarrow t_{0}} \frac{\frac{\Psi}{\tau_{1}}\left\|j \exp \left(\int \rho d t\right)\right\|}{\left\|j \exp \left(\int \rho d t\right)\right\|\|\rho\|}=\lim _{t \rightarrow t_{0}} \frac{\Psi}{\left\|\tau_{1} \rho\right\|}$

In the limit, when $t \rightarrow t_{0}$ :

$|E| \leq \frac{\Psi}{\left\|\tau_{1} \rho\right\|} \rightarrow 0$

As it is possible to note, it can be concluded that the regulation error lies on a closed ball of radius proportional to the quota of the uncertain term.

\section{NUMERICAL RESULTS AND ANALYSIS}

Figure 4 shows results of the modeling of the tubular reactor compared to experimental data, note an adequate performance of the proposed mathematical model. The considered parameters are $D=0.0115$ $\mathrm{m}^{2} / \mathrm{min}$; the initial length condition for the mass balance are $C_{C r}=273 \mathrm{mg} / \mathrm{l}$ at $\mathrm{z}=0 \quad \forall t$ and $\frac{\partial C_{C r}}{\partial t}=0$ at $z=0 \quad \forall t$, note that inlet concentration is considered as it is used in industry. The initial time condition for the mass balance is taken as $C_{C r}=50 \mathrm{mg} / \mathrm{l}$ for $\quad t=0 \quad \forall \mathrm{z}$. The reactor's inlet velocity (momentum boundary condition) is $v_{z}=0.18778 \mathrm{~m} / \mathrm{min}$ for $\quad z=0 \quad \forall t$ and the initial condition is $v=0 \mathrm{~m} / \mathrm{min}$ for $t=0 \quad \forall z$, the bound of the control law was consider to be $u_{\min }=0$ $\mathrm{m} / \mathrm{min}$ and $u_{\max }=0.5 \mathrm{~m} / \mathrm{min}$. 

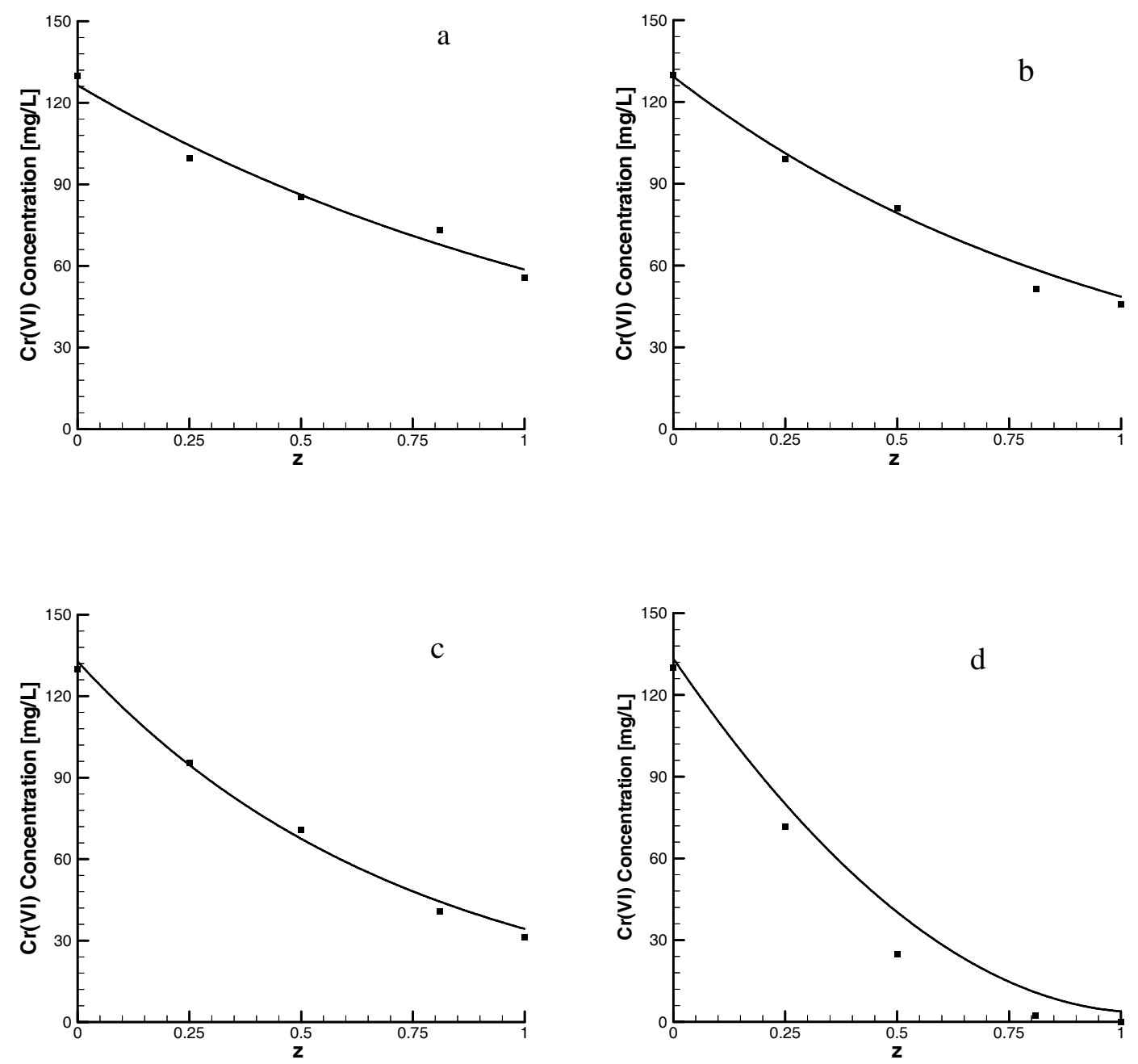

Figure 4. Experimental data ( $\square$ ) and ( $\_$numerical model results. (a) $T=4.68 \mathrm{~min}$, (b) $T=5.14 \mathrm{~min}$, (c) $T=6.0 \mathrm{~min}$, (d) $T=9.6 \mathrm{~min}$.

Figures 5 and 6 show the open-loop and closed-loop dynamic behavior of the $\mathrm{Cr}(\mathrm{VI})$ concentration at outlet reactor conditions. Note that the open-loop $\mathrm{Cr}(\mathrm{VI})$ trajectory reaches a steady state of $7.5 \mathrm{mg} / \mathrm{l}$, which is out of the maximum $\mathrm{Cr}(\mathrm{VI})$ concentration allowed $(0.5 \mathrm{mg} / \mathrm{l})$ by the environmental legislation; this operating mode is obviously inadequate. 


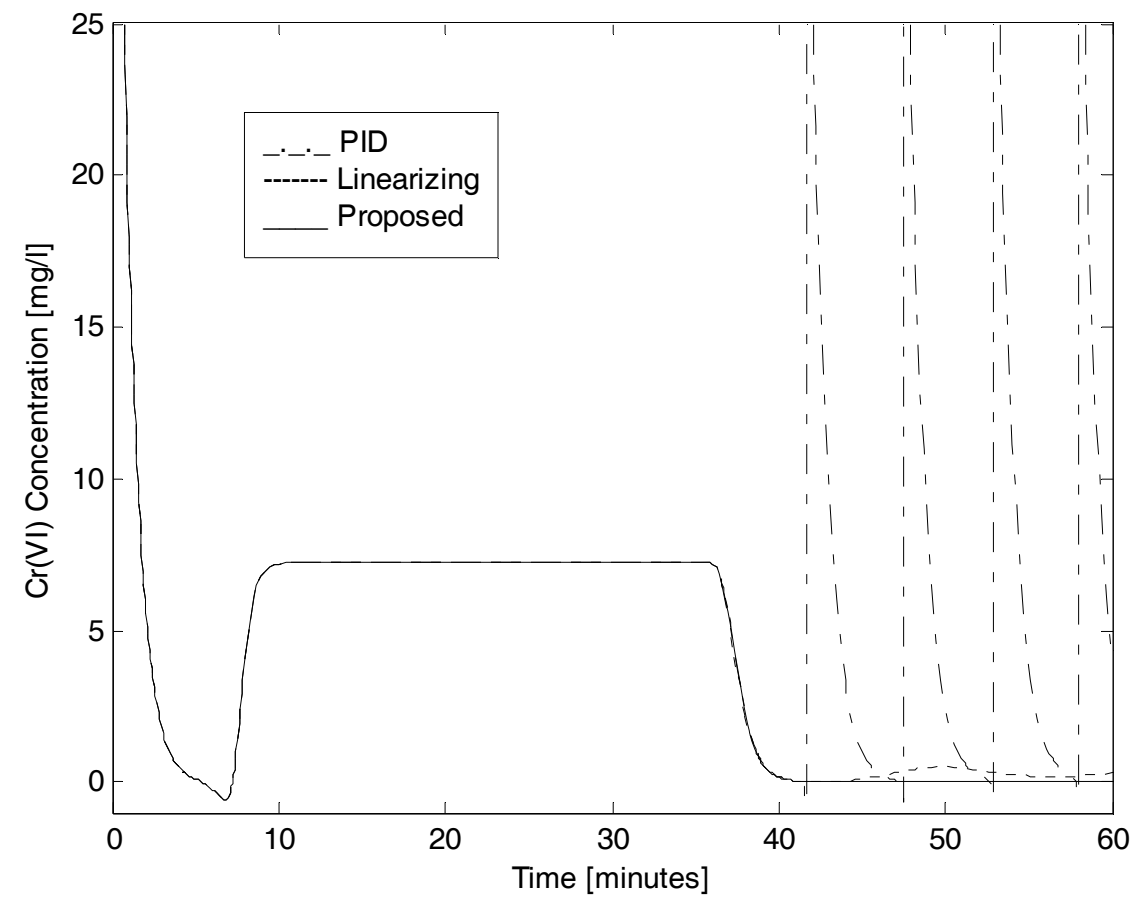

Figure 5. Cr(VI) concentration performance at reactor's outlet conditions.

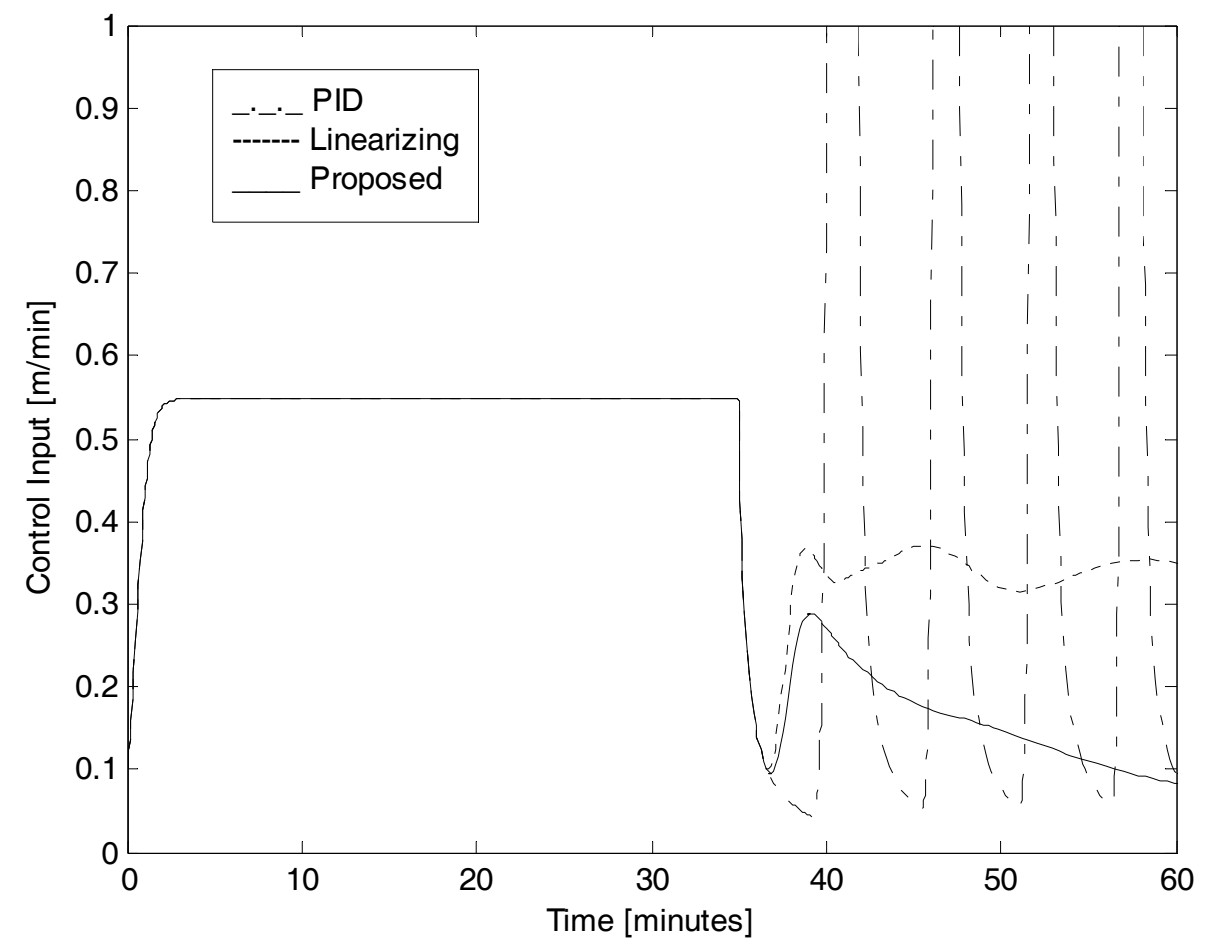

Figure 6. Control input efforts for the controllers compared. 
In order to regulate the process, the observer based GMC (OBGMC) designed exhibits observer's gains fixed at $\tau_{1}=2 \mathrm{~min}^{-1}$ and $\tau_{1}=0.1 \mathrm{~min}^{-1}$; the resulting gains for the OBGMC are $g_{1}{ }^{-1}=0.1 \mathrm{~min}^{-1}$ and $g_{2}^{-1}=0.1$ $\mathrm{min}^{-1}$. For comparison purposes, a observer based I/O linearizing controller (OBLC) with an equal proportional gain $\left(g_{1}^{-1}=0.1 \mathrm{~min}^{-1}\right)$ as OBGMC is considered and finally a linear PID controller is implemented to regulate the $\mathrm{Cr}(\mathrm{VI})$ concentration; for the linear controller, an Input/Output identification procedure was implemented with a step disturbance in the input flow of the order of the $5 \%$, where the corresponding steady state gain $\mathrm{K}=47.92(\mathrm{mg} \min ) /(\mathrm{l} \mathrm{m})$; the characteristic time $\tau=7.7$ minutes and the time delay is $\theta=1$ minute. From these values, a minimum ITAE approximate model controller tuning rules (Ogunnaike and Ray, 1994) was employed for the following controller's gains $\mathrm{g}_{\mathrm{p}}=0.1153(\mathrm{l} \mathrm{m}) /(\mathrm{mg}$ $\min ), \tau_{1}=9.91 \mathrm{~min}^{-1}$, and $\tau_{\mathrm{d}}=0.356 \mathrm{~min}^{-1}$. Following a common industrial practice, the controller was turned on at 35 minutes from the operation start.

Using the linear PID controller for the process, an oscillatory behavior is induced on the $\mathrm{Cr}(\mathrm{VI})$ concentration being out of the legislation requirements, this behavior would be induced by the nonlinear nature of the process and the associate lags for the distributed nature of the reactor. Control effort is also unacceptable, thus, the performance of the linear PID control law looks very poor. With respect to the OBLC, it can be seen the presence of large settling time; when the process starts, the estimation error is not small enough and it leads to a far from satisfactory closed-loop performance of the corresponding control effort. Finally, the proposed methodology acts keeping the controller at the minimum level for reaching the large residence time allowed and, consequently, diminishing the $\mathrm{Cr}(\mathrm{VI})$ concentration at the reactor's outlet (Figure 6), more over Figure 7 is related with the time delay present on the control input, which can induce some instabilities as mentioned above; however, for the proposed controller, it allows to reach a satisfactory continuous operation to maintain an adequate volumetric flow.

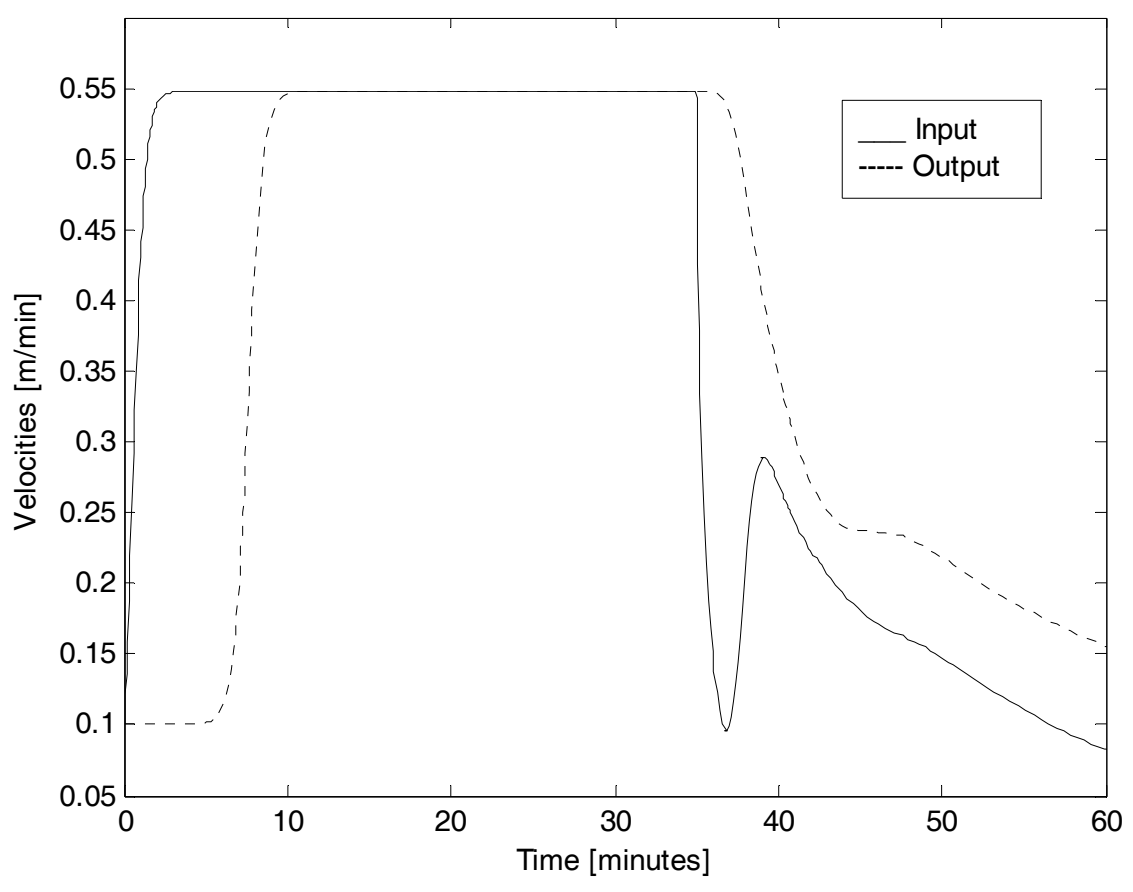

Figure 7 Delay on the control input (input velocity flow) 
In order to show the impact of the regulation error, a performance index suggested by Ogunnaike and Ray (1994) is the "Integral Time-Weighted Squared Error" (ITSE) defined by (27). ITSE exhibits the advantage of heavy penalization of large errors at long time; therefore, it is a good measure of resilience of the controller.

ITSE $=\int_{0}^{\infty} t \varepsilon^{2} d t$

Figure 8 shows the corresponding performances for the different controllers employed, note the bad behavior of the linear PID controller; on other hand, the OBLC shows a much better behavior, but the proposed control law provides the best performance, it is related with the integral action included in the control structure which, as it is well known, provides robustness.

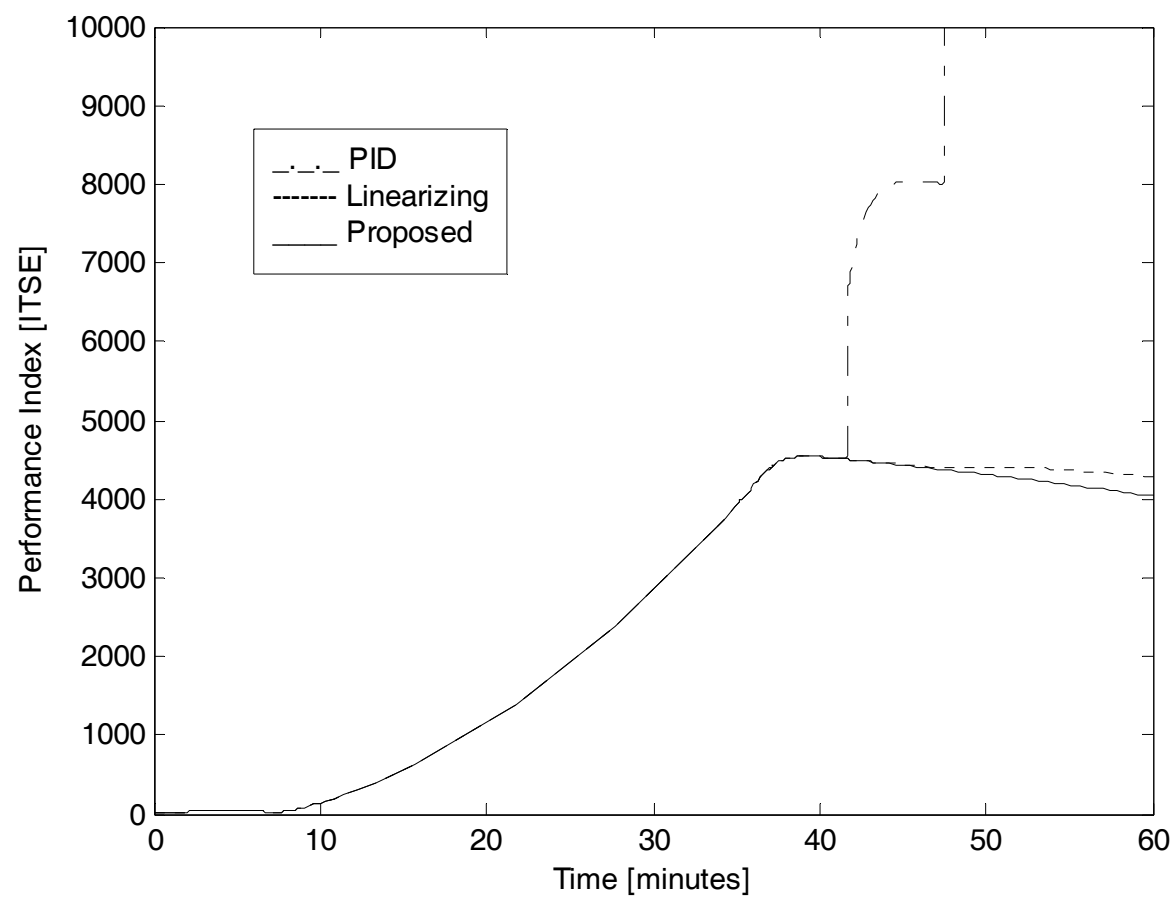

Figure 8. Delay on the control input (input velocity flow)

\section{CONCLUSIONS}

A tubular reactor for $\mathrm{Cr}(\mathrm{VI})$ reduction in plating wastewater is mathematically modeled for control purposes by a dynamic plug flow with dispersion term. This model is experimentally validated. Employing the distributed nature of the model (given by PDE), an observer based Generic Model Control is proposed; this controller is equivalent to PID plus double integral actions with time varying gains. The proposed methodology is robust against model uncertainties and provides a satisfactory closed-loop performance in comparison to other control strategies. 
Robust generic model feedback under model uncertainties: application of a tubular reactor for the treatment of industrial plating wastewater , R. Aguilar-López et al, 184-203

\section{REFERENCES}

[1] Ricardo Aguilar-López and Rafael Maya-Yescas. State Estimation for Nonlinear Systems under Model Uncertainties: A Class of Sliding-Mode Observers. J. Process Control 15, 363-370, 2005.

[2] R. Aguilar-López. Integral observers for uncertainty estimation in continuous chemical reactors: differential-algebraic approach. Chemical Engineering Journal. 2003. 9, 113-120.

[3] R. Aguilar, R.Martínez-Guerra, A. Poznyak and R. Maya-Yescas. Temperature control in catalytic cracking reactors via robust PID controller. Journal of Process Control. 12, 6, 695-705, 2002.

[4] Ricardo Aguilar-López and R. Maya-Yescas. State estimation for nonlinear systems under model uncertainties: A class of sliding-mode observers. Journal of Process Control. 2005, 15, 363-370.

[5] APHA, AWWA, WPCF. (1995) Standard Methods for the Examination of Water and Wastewater, 19th Ed. American Public health Association, Washington, D.C., U.S.A.

Balas, M.J. Feedback control of linear diffusion processes. Int. J. of Control. 29, 523-533, 1979.

[6] Chistofides P.D. Robust control of parabolic PDE systems. Chem. Eng. Sci. 53, 2949-2965, 1998.

[7] Chistofides P.D., Dautidis, P. Robust control of hyperbolic PDE systems. Chem. Eng. Sci. 53, 85105, 1998.

[8] Department of Health and Human Services. Chromium toxicity. Agency for Toxic Substances and Disease Registry, Division of Health Education and Promotion. Course: SS3048. 2000.

[9] Dochain, D, Babary, N, Tali-Mammar. Modeling and adaptive control of nonlinear distributed parameter bioreactors via orthogonal collocation. Automatica. 28, 873-883, 1992.

[10] Froment, G.F., Bischoff, K.B. Chemical reactor analysis and design. Wiley, New York, 1990.

[11] J. González, R. Aguilar, J. Alvarez-Ramírez and M. A. Barrón. Non-linear recursive feedback control for the regulation of substrate concentration in a fixed bed bioreactor. Journal of Chemical Technology and Biotechnology. 74, 766-770, 1999.

[12] Golub, D., and Oren, Y. Removal of Chromium from Aqueous Solutions by Treatment with Porous Carbon Electrodes: electrochemical principles. J.Appl. Electrochem, 19, 311-316, 1988.

[13] L. P. Lee and G.R. Sullivan. Generic Model Control. Computers and Chemical Engineering. 124, 573-580, 1988.

[14] Ogunnaike, B.A., Ray, W.H. Process Dynamics, Modeling and Control. Oxford University Press, New York, 1994.

[15] M. G. Rodríguez, R. Aguilar, G. Soto and S. A. Martínez. Modeling an electrochemical process to remove $\mathrm{Cr}(\mathrm{VI})$ from rinsing waters in a stirred reactor. Journal of Chemical Technology and Biotechnology. 78, 371-376, 2003.

[16] M.G. Rodríguez, S. A. Martínez, G. Soto and R. Aguilar. Performance evaluation of electrochemical reactors to remove $\mathrm{Cr}(\mathrm{VI})$ from rinsing waters from plating industry. Ingeniería Hidráulica en México. XIX, 4, 99-105, 2004. (In Spanish). 
[17] M. G. Rodríguez, R. Aguilar, G. Soto and S. Martínez. Removal of chromium hexavalent from rising chromatin waters by electrochemical reduction in a laboratory pilot plant. Water Science \& Technology. 49, 1, 115-122, 2004.

[18] Rönnbäck, S. Linear control of systems with actuators constraints. Ph D. dissertation. Lule University of Technology, Sweden, 1997.

[19] G. Soto, R. Aguilar and S. Martínez. Numerical modeling of a no-steady state flow in tubular reactor for treatment of industrial plating wastewater. Proceedings of the 5th IWA Chemical Industry Group Conference. 306-314, November, 2002, Nimes, France.

[20] P.D. Signal and P.L. Lee. Generic model adaptive control. Chemical Engineering Communications. 115, 35-52, 1992.

[21] Sussman, H.J., Kokotovic, P.V. The peaking phenomena and the global stabilization of nonlinear systems. IEEE Trans. On Automatic Control. 36, 424-431, 1991. 
Authors' Biography

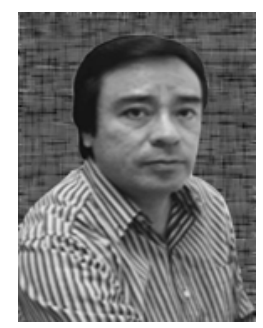

Ricardo Aguilar López

Born in Mexico City in 1964. He earns his BSc, MSc and PhD degrees from Universidad Autónoma Metropolitana in 1989, 1993 and 1998, respectively, all of them in chemical engineering. He was a postdoctoral fellow at Instituto Mexicano del Petróleo (2000); besides, he earns a Ph D in automatic control from CINVESTAV-IPN (2003). He works in robust observer design for nonlinear systems and process control. He is author and co-author of 83 papers published in international journals. Currently, he is a researcher at the Departamento de Biotecnología y Bioingeniería del Centro de Investigación y Estudios Avanzados del IPN and member of the Sistema Nacional de Investigadores since 1998 (level II, currently).

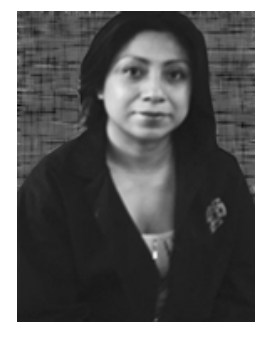

\section{María Isabel Neria González}

Born in Mexico City in 1971, she earns a degree in biochemical engineer from Universidad Autónoma Metropolitana (1999) and her M sc and Ph D degrees in microbiology science from Escuela Nacional de Ciencias Biológicas del IPN (2002 and 2006, respectively). She was a postdoctoral fellow at Departamento de Biotecnología y Bioingeniería del CINVESTAV-IPN and Microbiology Department of Provence University, France. She is author and/or coauthor of 11 published papers in indexed journals. Currently, she is a full-time professor at Tecnológico de Estudios Superiores de Ecatepec and candidate for national researcher at S.N.I.

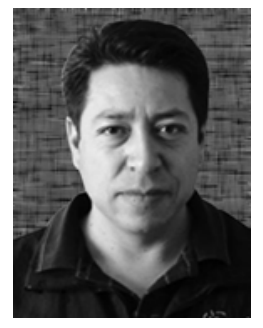

\section{Ricardo Acevedo Gómez}

Born in Mexico City, December 20 1969. He received his BSc degree from the Escuela Superior de Ingeniería Textil in Mexico City; his first degree studies were conducted at the Escuela Superior de Ingeniería Textil in linking with the Universidad Politécnica de Cataluña in Barcelona, Spain. Currently, 
he is pursuing doctoral studies in the Departamento de Biotecnología y Bioingeniería at the Centro de Investigaciones y Estudios Avanzados of the IPN (CINVESTAV-IPN), in Mexico City. His research experience involves the creation of a web page for troubleshooting related to electricity and magnetism, minimization of production costs in the making industry and detergency evaluation on different tinted and white cotton and polyester products. At present, $\mathrm{He}$ is carrying out research on variable estimation in biosystems using robust observers.

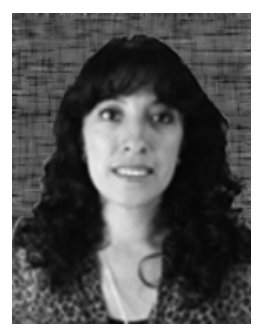

\section{Alma Rosa Domínguez Bocanegra}

Born in Mexico City in 1965. She earns a degree in biochemical engineering from Escuela Nacional de Ciencias Biológicas (1991) and the Ph D degree in biological sciences from Universidad Autónoma Metropolitana in 2003. She has been a research assistant in the Departamento de Bioingeniería y Biotecnología at the CINVESTAV-IPN, Mexico, since 1991 and a part-time professor at Tecnológico de Estudios Superiores de Ecatepec since 1992. She visited the university of Almeria and the Instituto de Bioquímica y Biosíntesis Vegetal at the CSIC in Sevilla, Spain, in 2002 and 2004, respectively. She works in microalgae biotechnology with pigment production and water bioremediation. She is author and/or coauthor of 20 papers published in indexed journals. She has been a member of the Sistema Nacional de Investigadores since 2000, (level I, currently). 